\title{
The effects of metformin in type 1 diabetes mellitus
}

\author{
Selvihan Beysel ${ }^{1,2^{*}}$ (D, Ilknur Ozturk Unsal ${ }^{3}$, Muhammed Kizilgul ${ }^{4}$, Mustafa Caliskan ${ }^{5}$, Bekir Ucan ${ }^{3}$ and Erman Cakal ${ }^{3}$
}

\begin{abstract}
Background: This retrospective study investigated the effect of adding metformin to pharmacologic insulin dosing in type 1 diabetics on insulin therapy 1 year after treatment compared with patients on insulin therapy alone.

Methods: Twenty-nine adults with type 1 diabetes who had metformin added to their insulin therapy for 12 months were compared with 29 adults with type 1 diabetes who remained on insulin-alone therapy.

Results: Fifty-eight patients with C peptide negative-type 1 diabetics (26 females, mean age: $29.01 \pm 7.03$ years, BMl: 24. $18 \pm 3.16 \mathrm{~kg} / \mathrm{m} 2$ ) were analyzed. Age, sex, body weight, insulin dose requirement, plasma glucose (PG), blood pressure (BP), and lipids did not differ between groups before treatment ( $p>0.05$ ). Metabolic syndrome (44.8 vs 41.4\%, $p>0.05$ ) did not differ between the metformin-insulin and insulin alone groups before treatment. Metabolic syndrome was more decreased in the metformin-insulin group than in the insulin alone group after treatment $(-8.9 \pm 1.3$ vs. $2.5 \pm 0.6 \%, p=0.028)$. Insulin dose requirement was lower in the metformin-insulin group than in the insulin alone group (-0.03 vs. $0.11 \mathrm{IU} / \mathrm{kg} / \mathrm{d}, p=0.006)$. Fasting PG (-26.9 \pm 54.2 vs. $0.7 \pm 29.5 \mathrm{mg} / \mathrm{dL}, p=0.022)$ and postprandial PG $(-43.1 \pm 61.8 \mathrm{mg} / \mathrm{dL}$ vs. $-3.1 \pm 40.1 \mathrm{mg} / \mathrm{dL}, p=0.010)$ was more decreased in the metformin-insulin group than in the insulin alone group. Body weight, lipids, and HbA1c did not differ between the groups ( $p>0.05$ ).

Conclusions: Metformin decreased glucose concentrations, reduced metabolic syndrome, as well as insulin dose requirement more than insulin therapy alone, 1 year after treatment. These results were independent of blood lipid improvement or weight loss, although on average weight remained decreased with metformin-insulin therapy, whereas the average weight increased with insulin therapy alone.
\end{abstract}

Keywords: Metformin, Type 1 diabetes, Insulin requirement

\section{Background}

Despite intensive insulin therapy, target hemoglobin $\mathrm{A}_{1 \mathrm{c}}$ $\left(\mathrm{HbA}_{1 \mathrm{c}}\right)$ levels remain above $7.0 \%$ in many patients with type 1 diabetes mellitus (DM) with poor metabolic control [1]. Standard insulin therapy in type 1 diabetes has been associated with increased complications including hypoglycemia, weight gain, and dyslipidemia [2]. Insulinstimulated skeletal muscle glucose uptake as well as insulin action reduces in type 1 diabetics. This effect contributes to the development of insulin resistance [3, 4]. Insulin resistance leads to poor glycemic control and chronic complications in type 1 diabetics $[5,6]$. Metabolic syndrome is a clinical proxy for insulin resistance. Type 1 diabetes

\footnotetext{
* Correspondence: beyselselvihan@gmail.com

'Department of Endocrinology and Metabolism, Eskisehir State Hospital, Eskisehir, Turkey

2Department of Medical Biology, Baskent University, Ankara, Turkey

Full list of author information is available at the end of the article
}

associated with metabolic syndrome has been termed as double diabetes [7-9]. Obesity [10], lack of exercise [11], and puberty [12] are primary causes of insulin resistance in type 1 diabetes. Management of insulin resistance usually requires an increase in insulin dose requirement. Increased insulin dose requirement might cause weight gain and hypoglycemia, which might lead to noncompliance with therapy and ultimately poor glycemic control [13].

Metformin is an oral anti-hyperglycemic agent and commonly used in the treatment of type 2 diabetes. It increases both hepatic and peripheral insulin sensitivity in the liver by inhibiting basal hepatic glucose production, as well as in skeletal muscles and adipocytes, by increasing glucose uptake $[4,14,15]$. Thus, it enhances insulin action and improves glycemic control. Metformin leads to reduce insulin dose requirement as well as weight gain because it increases insulin sensitivity. In this respect, compared with 
insulin monotherapy, the addition of metformin to insulin therapy improves metabolic control and decreases complications in type 2 diabetes [16]. Metformin has been shown to increase insulin sensitivity [17] and reduce metabolic syndrome incidence in people with prediabetes [18]. The addition of metformin to insulin therapy in type $1 \mathrm{DM}$ is still under debate. Until now, a limited number of studies have investigated the addition of metformin to insulin therapy in type 1 diabetics [4, 19-22]. Metformin as an adjunctive therapy is not formally recommended in type 1 diabetes unlike in type 2 diabetes [23].

This retrospective study investigated the effect of adding metformin to pharmacologic insulin dosing in type 1 diabetics on insulin therapy 1 year after treatment compared with patients on insulin therapy alone. This study aimed to investigate the effect of metformin, as an adjunctive therapy, on the treatment of poorly controlled type 1 diabetics.

\section{Methods}

Adults with C-peptide-negative type 1 diabetes were treated in Diskapi Yildirim Beyazit Training and Research Hospital, Endocrinology and Metabolism Department, between January 2010 and February 2013. Twenty-nine patients with type 1 diabetes had metformin added to their insulin therapy for 12 months. These patients were compared with 29 adults with type 1 diabetes who remained on insulin-alone therapy for 12 months. The inclusion criteria were as follows: age between 18 and 60 years, lack of metabolic control $\left(\mathrm{HbA}_{1 \mathrm{c}}\right.$ above $7.5 \%$ despite intensive insulin treatment), and complete medical data records. The exclusion criteria were as follows: lack of treatment adherence, renal impairment (estimated glomerular filtration rate lower than $60 \mathrm{~mL} / \mathrm{min}$ ) and liver disease (aminotransferase level higher than twice the upper normal limit). The patients were examined every 3 months. This retrospective study was approved and an informed consent was obtained from the patients.

\section{Clinical outcomes}

Metabolic syndrome, hypoglycemia, and drug adverse effects were recorded. Insulin dose requirement, blood pressure (BP), HbA1c, body mass index (BMI), fasting plasma glucose (FPG), postprandial plasma glucose (PPG), total cholesterol, triglyceride and low-density lipoprotein-cholesterol (LDL-C) and high-density lipoprotein-cholesterol (HDL-C) were compared before and after treatment. FPG and PPG were measured twice and average value was recorded. Insulin therapy and daily total insulin dose per bodyweight (IU/kg/d) were recorded. Office BP was measured before and after treatment. Office BP was measured with patients in the sitting position after 5 min of rest, provided that the arm was supported at heart level and the BP cuff covered about $80 \%$ of the circumference of the upper arm with the lower edge $2.5-3 \mathrm{~cm}$ above the elbow. Waist-circumference (WC) was measured midway between the lower costal margin and iliac crest, and hip circumference was measured at the height of the greater trochanter. Metabolic syndrome was defined according to the Adult Treatment Panel III criteria, and its diagnosis required three or more of the following: [1] WC $\geq 94 \mathrm{~cm}$ for men and $\geq 80 \mathrm{~cm}$ for women, [2] triglyceride $\geq 150 \mathrm{mg} / \mathrm{dL}$, [3] $\mathrm{HDL}-\mathrm{C}<40 \mathrm{mg} / \mathrm{dL}$ for men and $<50 \mathrm{mg} / \mathrm{dL}$ for women, [4] fasting glucose levels $\geq 100 \mathrm{mg} / \mathrm{dL}$, and [5] systolic BP $\geq 130 \mathrm{mmHg}$ and diastolic $\mathrm{BP} \geq 85 \mathrm{mmHg}$ [24].

\section{Statistical analysis}

Statistical analysis was performed using SPSS 18.0 (SPSS, Inc) software. Descriptive analyses are expressed as mean \pm standard deviation (SD), percentages (\%), median (min-max), odds ratio (OR), and 95\% confidence intervals (CI). Kolmogorov-Smirnov or Shapiro-Wilk W was used for normality. The Chi-square test or Fisher's exact test, where appropriate, was used for categorical variables. Student's t-test was used for normally distributed continuous variables. The Mann-Whitney $U$ test was used for nonparametric variables. McNemar's test was used for categorical variables before and after treatment. The paired samples t-test was used for parametric variables and the Wilcoxon test was used for nonparametric variables before and after treatment. The association between metabolic syndrome and insulin requirement was tested using Spearman's correlation coefficients. $p<0.05$ was accepted as statistically significant.

\section{Results}

The patients with type 1 diabetes ( 26 females, mean age: $29.01 \pm 7.03$ years, BMI: $24.18 \pm 3.16 \mathrm{~kg} / \mathrm{m}^{2}$ ) were retrospectively analyzed. The mean duration of diabetes was $12.05 \pm 6.53$ years. The mean metformin dose was $2124.2 \pm$ $524.2 \mathrm{mg} / \mathrm{d}$. Some $3.4 \%$ of patients in the metformin-insulin group were on continuous subcutaneous insulin infusion therapy and $96.6 \%$ were under intensified insulin therapy. All patients in insulin alone group were on intensified insulin therapy. There was no significant difference between the groups regarding age, sex, duration of diabetes, BMI, body weight, insulin dose requirement, waist circumference, systolic and diastolic blood pressure, lipids, hypertension, dyslipidemia, overweight/obesity and prevalence, and risk factors of metabolic syndrome before treatment $(p>0.05)$ (Table 1).

Change in body weight $(-0.41 \pm 2.44$ vs. $0.13 \pm 2.55 \mathrm{~kg}$, $p>0.05)$ and waist circumference $(-0.34 \pm 1.67$ vs. $0.41 \pm$ $1.61, p>0.05)$ did not differ between the metformininsulin and insulin alone groups after treatment. The increase in systolic BP $(6.72 \pm 6.16$ vs. $1.55 \pm 11.02 \mathrm{mmHg}$, $p=0.032)$ and diastolic BP (4.82 \pm 7.84 vs. $0.48 \pm 6.41 \mathrm{mmHg}$, 
Table 1 Characteristics of groups before treatment

\begin{tabular}{|c|c|c|c|}
\hline Variables & $\begin{array}{l}\text { Metformin-insulin } \\
n=29\end{array}$ & $\begin{array}{l}\text { Insulin-only } \\
n=29\end{array}$ & $p$ value \\
\hline Female (\%) & 41.4 & 48.3 & 0.597 \\
\hline Metabolic syndrome (\%) & 44.8 & 41.4 & 0.585 \\
\hline Overweight/obesity (\%) & 31.0 & 24.1 & 0.291 \\
\hline Hypertension (\%) & 27.6 & 13.8 & 0.195 \\
\hline Hyperlipidemia (\%) & 31.0 & 37.9 & 0.581 \\
\hline Antihypertensive drugs (\%) & 12.3 & 7.2 & 0.127 \\
\hline Antilipidemic drugs (\%) & 14.1 & 16.7 & 0.895 \\
\hline Age (yr) & $30.4 \pm 7.5$ & $27.5 \pm 6.3$ & 0.127 \\
\hline Duration of diabetes (yr) & $13.1 \pm 6.8$ & $10.9 \pm 6.1$ & 0.173 \\
\hline Body weight (kg) & $69.23 \pm 10.13$ & $66.96 \pm 11.50$ & 0.429 \\
\hline $\mathrm{BMI}\left(\mathrm{kg} / \mathrm{m}^{2}\right)$ & $24.43 \pm 2.87$ & $24.02 \pm 3.46$ & 0.446 \\
\hline Waist circumference $(\mathrm{cm})$ & $82.39 \pm 8.28$ & $80.65 \pm 9.59$ & 0.368 \\
\hline Risk factors of metabolic syndrome (n) & $2.27 \pm 1.13$ & $2.31 \pm 1.03$ & 0.904 \\
\hline Creatinine (mg/dl) & $0.81 \pm 0.19$ & $0.79 \pm 0.14$ & 0.124 \\
\hline FPG $(\mathrm{mg} / \mathrm{dl})$ & $192.37 \pm 56.01$ & $174.48 \pm 53.60$ & 0.232 \\
\hline PPG (mg/dl) & $277.31 \pm 57.43$ & $250.04 \pm 64.35$ & 0.100 \\
\hline $\mathrm{HbA}_{1 c}(\%)$ & $9.55 \pm 1.43$ & $9.22 \pm 1.79$ & 0.441 \\
\hline Total cholesterol (mg/dl) & $183.43 \pm 59.45$ & $177.25 \pm 26.89$ & 0.836 \\
\hline Triglycerides (mg/dl) & $141.93 \pm 131.33$ & $136.96 \pm 117.98$ & 0.844 \\
\hline HDL cholesterol (mg/dl) & $54.96 \pm 13.59$ & $50.28 \pm 11.68$ & 0.233 \\
\hline LDL cholesterol (mg/dl) & $105.46 \pm 39.25$ & $107.52 \pm 27.26$ & 0.566 \\
\hline Systolic blood pressure $(\mathrm{mmHg})$ & $122.75 \pm 16.74$ & $119.48 \pm 16.70$ & 0.441 \\
\hline Diastolic blood pressure (mmHg) & $78.13 \pm 12.76$ & $76.89 \pm 11.83$ & 0.690 \\
\hline Total daily insulin dose (IU/kg body weight/d) & $0.92 \pm 0.27$ & $0.98 \pm 0.30$ & 0.232 \\
\hline
\end{tabular}

Data are shown as mean \pm standard deviation (mean \pm SD) or percentage (\%)

Abbreviations: $B M I$ body mass index, $F P G$ fasting plasma glucose, $H b A_{1 c}$ hemoglobin $A_{1 c}, H D L$ high density lipoprotein, $L D L$ low density lipoprotein, $P P G$ postprandial plasma glucose, IU international units

$p=0.025)$ was significantly higher in the insulin alone group than in the metformin-insulin group (Table 2).

Insulin dose requirement decreased by $0.03 \mathrm{IU} / \mathrm{kg} / \mathrm{d}$ in the metformin-insulin group, whereas it increased by $0.11 \mathrm{IU} / \mathrm{kg} / \mathrm{d}$ in the insulin alone group after treatment. Insulin dose requirement was significantly increased in the insulin alone group compared with the metformininsulin group $(p=0.006)$ (Table 2$)$.

Metabolic syndrome prevalence ( 44.8 vs. $41.4 \%, p>0.05$ ) did not differ between the metformin-insulin group and the insulin alone group before treatment. Metabolic syndrome prevalence was significantly decreased in the metformin-insulin group compared with the insulin alone group after treatment $(-8.9 \pm 1.3$ vs. $2.5 \pm 0.6 \%, p=$ 0.028 , Table 2). The mean risk factors of metabolic syndrome was decreased in the metformin-insulin group $(2.27 \pm 1.13$ vs. $2.03 \pm 0.94, p=0.06)$, whereas it did not change in the insulin alone group $(2.31 \pm 1.03$ vs. $2.20 \pm$ $0.94, p=0.264)$. The patients in the metformin-insulin and insulin alone groups were divided into subgroups as metabolic syndrome and control non-metabolic syndrome. Metabolic syndrome percentage was decreased in the metformin-insulin group (44.8 vs. $37.9 \%, p=0.008)$ whereas it increased in the insulin alone group (41.4 vs. $44.8 \%, p=0.035)$.

A decrease in FPG of $26.9 \pm 54.2 \mathrm{mg} / \mathrm{dL}$ and PPG of $43.1 \pm 61.8 \mathrm{mg} / \mathrm{dl}$ was observed in the metformin-insulin group after treatment. A decrease in PPG of $3.1 \pm$ $40.1 \mathrm{mg} / \mathrm{dL}$ and an increase in FPG of $0.7 \pm 29.5 \mathrm{mg} / \mathrm{dL}$ were observed in the insulin alone group. There was a significant reduction in FPG $(p=0.022)$ and PPG $(p=$ 0.010 ) in the metformin-insulin group compared with the insulin alone group. The decrease in $\mathrm{HbA}_{1 \mathrm{c}}$ was not significantly different between the groups $(-0.8 \pm 1.4$ vs. $-0.3 \pm 1.3 \%, p>0.05)$. Changes in triglyceride, total cholesterol, LDL-C, and HDL-C did not differ between the groups after treatment $(p>0.05)$ (Table 2).

Lactic acidosis and vitamin B12 deficiency was not observed during treatment. Gastrointestinal discomfort (17.2\%) was observed in the metformin-insulin group. 
Table $\mathbf{2}$ Change in metabolic parameters after treatment

\begin{tabular}{|c|c|c|c|}
\hline Variables & $\begin{array}{l}\text { Metformin-insulin } \\
n=29\end{array}$ & $\begin{array}{l}\text { İnsulin-only } \\
n=29\end{array}$ & $p$ value \\
\hline$\triangle$ Metabolic syndrome prevalence (\%) & $-8.9 \pm 1.3$ & $2.5 \pm 0.6$ & 0.028 \\
\hline$\Delta$ Body weight (kg) & $-0.41 \pm 2.44$ & $0.13 \pm 2.55$ & 0.222 \\
\hline$\Delta$ Waist circumference $(\mathrm{cm})$ & $-0.34 \pm 1.67$ & $0.41 \pm 1.61$ & 0.384 \\
\hline$\triangle F P G(m g / d l)$ & $-26.9 \pm 54.2$ & $0.7 \pm 29.5$ & 0.022 \\
\hline$\triangle P P G(m g / d l)$ & $-43.1 \pm 61.8$ & $-3.1 \pm 40.1$ & 0.010 \\
\hline$\Delta \mathrm{HbA}_{1 \mathrm{c}}(\%)$ & $-0.8 \pm 1.4$ & $-0.3 \pm 1.3$ & 0.075 \\
\hline$\Delta$ Total cholesterol $(\mathrm{mg} / \mathrm{dl})$ & $-2.78 \pm 36.7$ & $-2.20 \pm 17.9$ & 0.962 \\
\hline$\Delta$ Triglycerides $(\mathrm{mg} / \mathrm{dl})$ & $-21.5 \pm 98.6$ & $-26.2 \pm 75.5$ & 0.855 \\
\hline$\Delta \mathrm{LDL}-\mathrm{C}(\mathrm{mg} / \mathrm{dl})$ & $-5.0 \pm 27.6$ & $-4.9 \pm 23.8$ & 0.899 \\
\hline$\Delta \mathrm{HDL}-\mathrm{C}(\mathrm{mg} / \mathrm{dl})$ & $0.43 \pm 9.65$ & $2.88 \pm 9.50$ & 0.522 \\
\hline$\triangle$ Systolic blood pressure $(\mathrm{mmHg})$ & $1.55 \pm 11.02$ & $6.72 \pm 6.16$ & 0.032 \\
\hline$\Delta$ Diastolic blood pressure $(\mathrm{mmHg})$ & $0.48 \pm 6.41$ & $4.82 \pm 7.84$ & 0.025 \\
\hline$\Delta$ Total daily insulin dose (IU/kg bodyweight/d) ${ }^{a}$ & $-0.03(-0.39-0.28)$ & $0.11(-0.24-0.35)$ & 0.006 \\
\hline
\end{tabular}

Data are shown as mean \pm standard deviation (means \pm SD) and ${ }^{a}$ median (min-max)

The difference $(\Delta)$ are shown as change in values before and after treatment (after value minus before value)

Abbreviations: FPG fasting plasma glucose, $H b A_{1 c}$ hemoglobin $A_{1 c}, P P G$ postprandial plasma glucose, $H D L-C$ high density lipoprotein-cholesterol, $L D L-C$ low density lipoprotein-cholesterol, IU international units

Bold represents the significant $p$-values

Hypoglycemic events did not differ between the groups (7.1 and $7.6 \%, p>0.05)$.

The decrease in metabolic syndrome prevalence was not correlated with a reduction in insulin dose requirement $(r=0.45, p=0.23)$. The decrease in insulin dose requirement was positively correlated with the reduction in fasting glucose $(r=0.487, p<0.001)$ and postprandial glucose $(r=0.774, p<0.001)$.

\section{Discussion}

This retrospective study suggests that metformin decreased glucose concentrations, lowered metabolic syndrome prevalence, as well as insulin dose requirement more than insulin therapy alone after 1 year of treatment. These results were independent of blood lipid improvement or weight loss, although on average weight remained decreased with metformin and insulin therapy, whereas the average weight increased with insulin therapy alone.

Studies of adolescents [18], pediatrics [22], adults [4], and overweight adults [19-21] with type 1 diabetes have been shown the addition of metformin to insulin therapy to reduce insulin dose requirement. Metformin was suggested to reduce insulin dose requirement through its insulin-sparing effect $[4,15,25]$. The present study suggests that metformin decreased average glucose concentrations and insulin dose requirement, as well as lowered metabolic syndrome prevalence more than with insulin therapy alone after 1 year of treatment. Metformin decreased HbAlc values more than insulin alone, but not significantly. These results were independent of blood lipid improvement or weight loss. We suggest that metformin likely improved glycemic control more than with insulin alone and this also contributed to metabolic syndrome reductions. Metformin has been shown to have an insulin-sensitizing effect on glycemic control in type 1 diabetes $[17,20]$. Nevertheless, metformin has been shown to reduce insulin dose requirement without improving glycemic control such as with glucose concentration, as well as HbA1c in type 1 diabetes [4, 20,21]. Jacobsen et al. reported that metformin reduced the insulin dose requirement without improving glycemic control or weight loss after 6 months' treatment in overweight adults with type 1 diabetic [21]. Lund et al. suggested that metformin achieved permanent inadequate glycemic control with reducing insulin dose requirement and improved body weight during 12 months' treatment [4]. Urakami et al. observed that metformin reduced insulin dose requirement, improved glycemic control, and reduced body weight after 12 months' treatment in overweight young adults with type 1 diabetes [25]. Moon et al. reported that metformin improved glycemic control and insulin sensitivity without weight gain after 3 months' therapy [26]. Metformin improved diabetic control with reduced insulin dose requirement without weight loss in overweight adults with C-peptide-negative type 1 diabetes during 4 months' therapy [19]. Metformin improved poor glycemic control as well as insulin resistance in adolescents with type 1 diabetes who were on high-dose insulin therapy $[17,18]$.

Previous studies reported that metformin improved the blood lipid profile [26-28]. Burchardt et al. reported that metformin increased insulin sensitivity in peripheral 
tissues and reduced LDL-C concentrations with improved glycemic regulation, as well as weight loss, in overweight adults [27]. The present study suggests that metformin reduced glucose concentration and decreased insulin dose requirement without blood lipid improvement and weight loss. On average weight remained decreased on metformin and insulin therapy, whereas the average weight increased in the insulin alone group. There was a decrease in relatively normal lipid values in the metformin-insulin group compared with the insulin alone group; however, these results were not significant. There was a greater increase in systolic and diastolic blood pressure in the insulin alone group compared with the metformin-insulin group. These results might contribute to improved metabolic syndrome status with metformin therapy.

Previous studies have not systematically tested metformin in patients with metabolic syndrome with T1DM. Metformin likely reduced metabolic syndrome percentage in present study. Insulin resistance accompanied by type 1 diabetes causes the development of double diabetes and poorer glycemic control [5, 6, 9, 29]. Metformin reduces hepatic glucose production, stimulates glucose uptake in muscle, as well as improves blood flow for nutrient use. Metformin increases insulin sensitivity, reduces insulin resistance, improves insulin action, and increases peripheral glucose uptake in type 1 diabetes [18, 20, 21, 26]. Patients with $C$ peptide-negative diabetes were included in this study in order to ignore metformin effects on beta cell function; metformin correlates with insulin resistance and beta-cell function. Hypoglycemic events [4, 20-22], lactic acidosis or vitamin B12 deficiency [26] were not observed in our metformin therapy group. However, this was a small and retrospective study, the study was not randomized or placebo-controlled and diet was not standardized prior to testing. All of which are limitations to our study.

\section{Conclusions}

The present study suggests that metformin decreased glucose concentrations, lowered metabolic syndrome prevalence, as well as insulin dose requirement, more than insulin alone. These effects were independent of blood lipid improvement or weight loss, although on average weight remained decreased with metformin and insulin therapy, whereas the average weight increased with insulin therapy alone. Larger placebo-controlled studies are needed to determine the long-term effects of metforminadjunctive therapy on poorly controlled type 1 diabetes.

\section{Abbreviations}

BMl: Body mass index; BP: Blood pressure; DM: Diabetes mellitus; FBP: Fasting plasma glucose; $\mathrm{HbA}_{1 c}$ : Hemoglobin $\mathrm{A}_{1 \mathrm{c}} ; \mathrm{HDL}-\mathrm{C}$ : High-density lipoproteincholesterol; LDL-C: Low-density lipoprotein-cholesterol; PPG: Postprandial plasma glucose; TG: Triglyceride; WC: Waist-circumference

\section{Acknowledgements}

None

\section{Funding}

No funding sources for research.

Availability of data and materials

The datasets used and/or analysed during the current syudy available from the corresponding author on reasonable request.

\section{Authors' contributions}

SB contributions to conception and design, or acquisition of data, or analysis and interpretation of data, involved in drafting the manuscript; IOU contributions to conception and design, or acquisition of data, or analysis and interpretation of data; MK, MC, BU acquisition of data, or analysis and interpretation of data; EC revising it critically for important intellectual content; and have given final approval of the version to be published. All authors read and approved the final manuscript.

\section{Ethics approval and consent to participate}

This retrospective study was approved by Diskapi Yildirim Beyazit Teaching and Research Hospital Ethics Board (No: 26.01.2015-19/21) and written informed consent of participants were obtained before the study.

Consent for publication

Non applicable

\section{Competing interests}

The authors declare that they have no competing interests.

\section{Publisher's Note}

Springer Nature remains neutral with regard to jurisdictional claims in published maps and institutional affiliations.

\section{Author details}

'Department of Endocrinology and Metabolism, Eskisehir State Hospital, Eskisehir, Turkey. ${ }^{2}$ Department of Medical Biology, Baskent University, Ankara, Turkey. ${ }^{3}$ Department of Endocrinology and Metabolism, Ankara Diskapi Teaching and Research Hospital, Ankara, Turkey. ${ }^{4}$ Department of Endocrinology and Metabolism, Kilis State Hospital, Kilis, Turkey. ${ }^{5}$ Department of Endocrinology and Metabolism, Duzce Ataturk State Hospital, Duzce, Turkey.

Received: 16 March 2017 Accepted: 10 December 2017 Published online: 16 January 2018

\section{References}

1. Chiang JL, Kirkman MS, Laffel LMB, Peters AL, Type 1 Diabetes Sourcebook Authors. Type 1 diabetes through the life span: a position statement of the American Diabetes Association. Diabetes Care. 2014;37:2034-54.

2. Purnell JQ, Hokanson JE, Marcovina SM, Steffes MW, Cleary PA, Brunzell JD. Effect of excessive weight gain with intensive therapy of type 1 diabetes on lipid levels and blood pressure: results from the DCCT. Diabetes control and complications trial. JAMA. 1998;280:140-6.

3. Orchard TJ, Olson JC, Erbey JR, Williams K, Forrest KY-Z, Smithline Kinder L, Ellis D, Becker DJ. Insulin resistance-related factors, but not glycemia, predict coronary artery disease in type 1 diabetes: 10-year follow-up data from the Pittsburgh Epidemiology of Diabetes Complications Study. Diabetes Care. 2003:26:1374-9.

4. Lund SS, Tarnow L, Astrup AS, Hovind P, Jacobsen PK, Alibegovic AC, Parving I, Pietraszek L, Frandsen M, Rossing P, et al. Effect of adjunct metformin treatment in patients with type-1 diabetes and persistent inadequate glycaemic control. A randomized study. PLoS One. 2008;3:e3363.

5. Pop A, Clenciu D, Anghel M, Radu S, Socea B, Mota E, Mota M, Panduru NM, RomDianeStudy Group. Insulin resistance is associated with all chronic complications in type 1 diabetes. J Diabetes. 2016:8(2):220-8.

6. Krochik AG, Botto M, Bravo M, Hepner M, Frontroth JP, Miranda M, Mazza C. Association between insulin resistance and risk of complications in children and adolescents with type 1 diabetes. Diabetes Metab Syndr. 2015;9:14-8.

7. Thorn LM, Forsblom C, Fagerudd J, Thomas MC, Pettersson-Fernholm K, Saraheimo M, Wadén J, Rönnback M, Rosengård-Bärlund M, Björkesten C-GA, 
et al. Metabolic syndrome in type 1 diabetes: association with diabetic nephropathy and glycemic control (the FinnDiane study). Diabetes Care. 2005; 28:2019-24.

8. Metascreen Writing Committee, Bonadonna RC, Cucinotta D, Fedele D, Riccardi G, Tiengo A. The metabolic syndrome is a risk indicator of microvascular and macrovascular complications in diabetes: results from Metascreen, a multicenter diabetes clinic-based survey. Diabetes Care. 2006;29:2701-7.

9. Kilpatrick ES, Rigby AS, Atkin SL. Insulin resistance, the metabolic syndrome, and complication risk in type 1 diabetes: "double diabetes" in the diabetes control and complications trial. Diabetes Care. 2007;30:707-12.

10. Lauria A, Barker A, Schloot N, Hosszufalusi N, Ludvigsson J, Mathieu C, Mauricio D, Nordwall M, Van der Schueren B, Mandrup-Poulsen T, et al. BMl is an important driver of $\beta$-cell loss in type 1 diabetes upon diagnosis in 10 to 18-year-old children. Eur J Endocrinol Eur Fed Endocr Soc. 2015;172:107-13.

11. Yardley JE, Kenny GP, Perkins BA, Riddell MC, Goldfield GS, Donovan L, Hadjiyannakis S, Wells GA, Phillips P, Sigal RJ, et al. Resistance Exercise in Already-Active Diabetic Individuals (READI): study rationale, design and methods for a randomized controlled trial of resistance and aerobic exercise in type 1 diabetes. Contemp Clin Trials. 2015:41:129-38.

12. Sorensen JS, Birkebaek NH, Bjerre M, Pociot F, Kristensen K, Hoejberg AS, Frystyk J, Danish Society for Diabetes in Childhood and Adolescence. Residual $\beta$-cell function and the insulin-like growth factor system in Danish children and adolescents with type 1 diabetes. J Clin Endocrinol Metab. 2015;100:1053-61.

13. Dejgaard TF, Knop FK, Tarnow L, Frandsen CS, Hansen TS, Almdal T, Holst JJ, Madsbad S, Andersen HU. Efficacy and safety of the glucagon-like peptide-1 receptor agonist liraglutide added to insulin therapy in poorly regulated patients with type 1 diabetes-a protocol for a randomised, double-blind placebo-controlled study: the Lira-1 study. BMJ Open. 2015;5:e007791.

14. Inzucchi SE, Maggs DG, Spollett GR, Page SL, Rife FS, Walton V, Shulman GI. Efficacy and metabolic effects of metformin and troglitazone in type II diabetes mellitus. N Engl J Med. 1998;338:867-72.

15. George P, McCrimmon RJ. Potential role of non-insulin adjunct therapy in Type 1 diabetes. Diabet Med J Br Diabet Assoc. 2013;30:179-88.

16. UK Prospective Diabetes Study (UKPDS) Group. Effect of intensive bloodglucose control with metformin on complications in overweight patients with type 2 diabetes (UKPDS 34). Lancet. 1998;352:854-65.

17. Hamilton J, Cummings E, Zdravkovic V, Finegood D, Daneman D. Metformin as an adjunct therapy in adolescents with type 1 diabetes and insulin resistance: a randomized controlled trial. Diabetes Care. 2003;26:138-43.

18. Särnblad S, Kroon M, Aman J. Metformin as additional therapy in adolescents with poorly controlled type 1 diabetes: randomised placebo-controlled trial with aspects on insulin sensitivity. Eur J Endocrinol Eur Fed Endocr Soc. 2003; 149:323-9.

19. Khan ASA, McLoughney CR, Ahmed AB. The effect of metformin on blood glucose control in overweight patients with type 1 diabetes. Diabet Med J Br Diabet Assoc. 2006;23:1079-84.

20. Meyer L, Bohme P, Delbachian I, Lehert P, Cugnardey N, Drouin P, Guerci B. The benefits of metformin therapy during continuous subcutaneous insulin infusion treatment of type 1 diabetic patients. Diabetes Care. 2002;25:2153-8.

21. Jacobsen IB, Henriksen JE, Beck-Nielsen $H$. The effect of metformin in overweight patients with type 1 diabetes and poor metabolic control. Basic Clin Pharmacol Toxicol. 2009;105:145-9.

22. Konrad K, Datz N, Engelsberger I, Grulich-Henn J, Hoertenhuber T, Knauth B, Meissner T, Wiegand S, Woelfle J, Holl RW, et al. Current use of metformin in addition to insulin in pediatric patients with type 1 diabetes mellitus: an analysis based on a large diabetes registry in Germany and Austria. Pediatr Diabetes. 2015;16:529-37.

23. DeGeeter M, Williamson B. Alternative agents in type 1 diabetes in addition to insulin therapy: Metformin, alpha-Glucosidase inhibitors, Pioglitazone, GLP-1 agonists, DPP-IV inhibitors, and SGLT-2 inhibitors. J. Pharm Pract. 2016;29(2):144-59.

24. National Cholesterol Education Program (NCEP) Expert Panel on Detection, Evaluation, and Treatment of High Blood Cholesterol in Adults (Adult Treatment Panel III). Third report of the National Cholesterol Education Program (NCEP) expert panel on detection, evaluation, and treatment of high blood cholesterol in adults (adult treatment panel III) final report. Circulation. 2002;106:3143-421.

25. Urakami T, Morimoto S, Owada M, Harada K. Usefulness of the addition of metformin to insulin in pediatric patients with type 1 diabetes mellitus. Pediatr Int Off J Jpn Pediatr Soc. 2005;47:430-3.
26. Moon RJ, Bascombe, L-A, Holt RIG. The addition of metformin in type 1 diabetes improves insulin sensitivity, diabetic control, body composition and patient well-being. Diabetes Obes Metab. 2007;9:143-5.

27. Burchardt $P$, Zawada A, Tabaczewski $P$, Naskręt D, Kaczmarek J, Marcinkaniec J, Wierusz-Wysocka B, Wysocki H. Metformin added to intensive insulin therapy reduces plasma levels of glycated but not oxidized low-density lipoprotein in young patients with type 1 diabetes and obesity in comparison with insulin alone: a pilot study. Pol Arch Med. Wewnętrznej. 2013;123:526-32.

28. Lund SS, Tarnow L, Astrup AS, Hovind P, Jacobsen PK, Alibegovic AC, Parving I, Pietraszek L, Frandsen M, Rossing P, et al. Effect of adjunct metformin treatment on levels of plasma lipids in patients with type 1 diabetes. Diabetes Obes Metab. 2009;11:966-77.

29. Schwab KO, Doerfer J, Hecker W, Grulich-Henn J, Wiemann D, Kordonouri O, Beyer P, Holl RW, DPV Initiative of the German Working Group for Pediatric Diabetology. Spectrum and prevalence of atherogenic risk factors in 27,358 children, adolescents, and young adults with type 1 diabetes: cross-sectional data from the German diabetes documentation and quality management system (DPV). Diabetes Care. 2006;29:218-25.

\section{Submit your next manuscript to BioMed Central and we will help you at every step:}

- We accept pre-submission inquiries

- Our selector tool helps you to find the most relevant journal

- We provide round the clock customer support

- Convenient online submission

- Thorough peer review

- Inclusion in PubMed and all major indexing services

- Maximum visibility for your research

Submit your manuscript at www.biomedcentral.com/submit
Ciomed Central 